\title{
Construcción del dato oficial y realidad institucional: disminución del flujo indocumentado en los registros del INM
}

\author{
Rodolfo Casillas R.
}

Resumen. En lo que va del siglo xxi, la transmigración indocumentada internacional que pasa por México ha llamado la atención de la opinión pública debido a los secuestros masivos y asesinatos colectivos, hechos inéditos en la historia reciente. En el contexto de la crisis económica en Estados Unidos, de alcance mundial, y ante aquellos acontecimientos violentos, era lógico preguntarse si la transmigración disminuiría, en qué proporción y por cuánto tiempo. Las estadísticas del Instituto Nacional de Migración (INM) de México parecieran indicar una disminución del flujo, así sea temporal, al menos de quienes son capturados y devueltos por la autoridad migratoria mexicana. Por la importancia de la transmigración internacional que transita por México, se analizan los argumentos oficiales y se presentan otros elementos de juicio que hacen dudar sobre qué tan cierta es dicha disminución. Palabras clave: transmigración internacional, migrantes indocumentados, INM, deportaciones, dato oficial.
Aвstract. International undocumented transmigration via Mexico has become a source of public attention during the 21st century, in particular due to ongoing mass abductions and collective murders unparalleled in recent history. Given the U.s. economic crisis, its global effect, and those violent events, it made sense to wonder whether transmigration would diminish, to what extent and for how long. Data issued by Mexico's National Migration Institute seem to indicate a decrease in flow, however temporary - at least among those who are caught and deported by Mexican immigration authorities. Given the importance of the international transmigration flow that passes through Mexico, this paper takes a look at official arguments as well as information not presented by the government, casting doubt on this presumed decline and pondering how much of it could be a product of official stances. KEYwords: International transmigration, undocumented migrants, INM, deportations, official data.

Rodolfo Casillas R. es profesor e investigador de la Facultad Latinoamericana de Ciencias Sociales (Flacso), sede académica de México. Correos electrónicos: ‘rodolfo.casillas@flacso.edu.mx〉y ‘casillassan@gmail.com〉. 


\section{INTRODUCCIÓN: EL DATO OFICIAL}

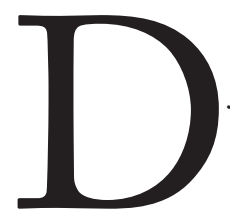

esde los últimos decenios del siglo xx hasta la fecha, los flujos migratorios de indocumentados que engrosan mayoritariamente las estadísticas de detenidos por el Instituto Nacional de Migración (INM) son de origen guatemalteco, hondureño, salvadoreño y nicaragüense ${ }^{1}$ (véase el cuadro 1). Las mismas estadísticas gubernamentales muestran un crecimiento constante en el total de eventos de detención hasta 2005 y, después, una caída notoria en el registro con una posterior recuperación, sin llegar a la cifra más alta (véase el cuadro 2).

\section{CUADRO I}

Devoluciones y rechazos de extranjeros, por nacionalidad, realizados por el Instituto Nacional de Migración de México, 1990-2000.

\begin{tabular}{ccccccc}
\hline AÑO & GUATEMALA & EL SALVADOR & HONDURAS & NICARAGUA & OTROS & TOTAL \\
\hline 1990 & 58845 & 45598 & 14954 & 3039 & 4004 & 136440 \\
1991 & 69991 & 40441 & 18419 & 1265 & 3226 & 133342 \\
1992 & 65304 & 26643 & 25546 & 1632 & 3871 & 123046 \\
1993 & 58910 & 28646 & 26734 & 3438 & 4277 & 122005 \\
1994 & 42961 & 22794 & 32414 & 12330 & 2616 & 113115 \\
1995 & 52051 & 19526 & 27236 & 2521 & 4686 & 105040 \\
1996 & 50497 & 20904 & 31055 & 1878 & 2784 & 107110 \\
1997 & 37837 & 18857 & 24890 & 1172 & 2832 & 85588 \\
1998 & 46088 & 25783 & 35161 & 1854 & 2636 & 111572 \\
1999 & 50924 & 26176 & 44818 & 1394 & 3106 & 126498 \\
2000 & 79431 & 37481 & 45802 & 1960 & 8261 & 172935 \\
Total & 612839 & 312849 & 327029 & 32533 & 42349 & 1327599 \\
\hline
\end{tabular}

Fuente: ‘www.inm.gob.mx〉.

${ }^{11 /}$ En años recientes, estos últimos han perdido su importancia relativa frente al auge de otras nacionalidades, como la ecuatoriana. 
Los registros del último decenio del siglo $\mathrm{xx}$ son indicativos de un volumen considerable de migrantes indocumentados detenidos, originarios de Centroamérica. En este punto, cabe hacer una precisión de carácter técnico: la estadística gubernamental da cuenta de eventos de devoluciones y no de personas; esto quiere decir que una persona pudo y puede ser detenida por el INM varias veces en un mismo año, lo que arroja una duda sobre el número de personas que conforman realmente cada cálculo oficial. Se trata de una interrogante que sigue siendo un desafio a la creatividad de funcionarios y analistas.

\section{CUADRO 2}

Devoluciones y rechazos de extranjeros, por nacionalidad, realizados por el Instituto Nacional de Migración de México, 2001-2010.

\begin{tabular}{cccccccc}
\hline AÑo & GUATEMAla & HONDURAs & EL SAlVAdor & NICARAGUA & $\begin{array}{c}\text { TOtAL } \\
\text { PARCIAL }\end{array}$ & OTRos & TOTAL \\
\hline 2001 & 67522 & 40105 & 35007 & 1712 & 144346 & 6184 & 150530 \\
2002 & 67336 & 41801 & 20800 & 1609 & 131546 & 6515 & 138061 \\
2003 & 86023 & 61900 & 29301 & 2150 & 179374 & 8240 & 187614 \\
2004 & 94404 & 72684 & 34572 & 2453 & 204113 & 11582 & 215695 \\
2005 & 100948 & 78326 & 42674 & 3980 & 225928 & 14341 & 240269 \\
2006 & 84523 & 58001 & 27287 & 3590 & 173401 & 9304 & 182705 \\
2007 & 14939 & 22980 & 5777 & 855 & 44551 & 7149 & 51700 \\
2008 & 11656 & 16624 & 4233 & 626 & 33139 & 6297 & 39436 \\
2009 & 29604 & 24040 & 10355 & 53 & 64052 & 4981 & 69033 \\
2010 & 28933 & 23811 & 10567 & 839 & 64150 & 5753 & 69903 \\
Total & 585888 & 440272 & 220573 & 17867 & 1264600 & 80346 & 1344946 \\
\hline
\end{tabular}

Fuente: «www.inm.gob.mx〉.

¿De qué depende que una persona sea detenida varias veces? Depende de una o varias razones: experiencia migratoria; concurso y éxito de una red de acompañamiento, y éxito de la política gubernamental en la detección y detención del migrante indocumentado. Más adelante se verá cómo estos elementos inciden en el total de eventos de captura de indocumentados por el INM. 
Para el primer decenio del siglo xxi, la situación se presenta en el cuadro 2, y la supuesta reducción del flujo se observa mejor en la gráfica 1 .

¿Cómo se explica la caída en el registro desde la óptica gubernamental? La explicación es multicausal, con peso relativo en cada uno de los componentes, con la conjugación de lo ocurrido en Estados Unidos, México y Centroamérica. Básicamente, son tres los argumentos: I) la política de contención migratoria de Estados Unidos; 2) la crisis económica de Estados Unidos, lo que hace disminuir la demanda y, en consecuencia, contrae la oferta de mano de obra; 3) la inseguridad pública en México, en particular la confrontación entre el crimen organizado y las autoridades mexicanas, así como el conflicto intracárteles.

\section{GRÁFICA I}

Extranjeros detenidos en estaciones migratorias, según nacionalidad, 2001-2011, INM, México.

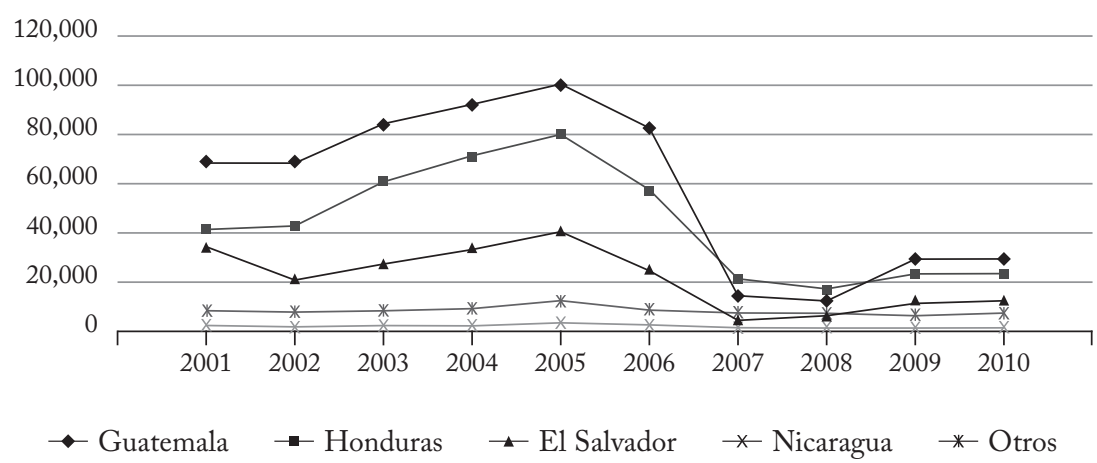

Fuente: «www.inm.gob.mx〉.

La conjugación de estos tres elementos explicaría la disminución del flujo según las fuentes gubernamentales de México, las cuales, como elemento de respaldo, hacen referencia a fuentes estadísticas de Estados Unidos, que también registran una disminución en las detenciones de indocumentados centroamericanos. Esto sería la prueba de que los datos del INM son correc- 
tos, y aunque no resulte convincente que la posible validación del registro mexicano se deba a la eventual coincidencia con lo que se diga en Estados Unidos, ése es el argumento. Empero, cabe preguntarse si, en efecto, esos argumentos son sólidos y suficientes para explicar la disminución en el registro estadístico del INM.

\section{LA CONSTRUCCIÓN INSTITUCIONAL DEL DATO ESTADÍSTICO}

Lo primero que habría que decir es que una cosa es cómo se construye el dato estadístico y otra cómo se interpreta dicho dato. ${ }^{2}$ Hasta el momento, sigue siendo una incógnita la metodología utilizada por el INM para la construcción del dato; lo único que se sabe es que sus delegaciones regionales (en realidad estatales, pues hay una por entidad federativa) captan directamente la información, le dan un determinado tratamiento y en las oficinas centrales - en concreto, en el Centro de Estudios Migratorios del INM - la procesan y posteriormente publican los resultados en versión impresa y digital. Pero cómo se trabaja en las delegaciones para captar el dato y cuáles son las fases técnicas en las delegaciones y en el Centro, es algo que no se da a conocer. En consecuencia, se tiene que suponer que todo ese proceso, tan delicado e importante, se hace bien y sin error. Aunque debiera haber transparencia en esa parte de la administración pública federal, lo cierto es que, por lo pronto, no la hay, por lo que no es posible hacer un pronunciamiento sobre cómo se construyó el dato oficial. De cualquier manera, quien haya verificado la actuación del personal, el cual no siempre está capacitado, y las condiciones

${ }^{12 /}$ La postura de las autoridades del INM ha sido difundida por distintos medios, impresos y virtuales, así como en conferencias y foros diversos. Un ejemplo de ello se encuentra en el ejemplar de agosto de 2011 de Apuntes sobre migración, número 1, pu- 
y las circunstancias en que se llega a trabajar, puede abrigar reservas sobre la captura y el tratamiento primero del dato estadístico. No obstante, pese a no saber con certeza cómo se construye el dato, lo que sí se puede hacer es analizar dicho dato. Aquí se hará de manera contextual, a partir de lo que ocurre en México y de la elaboración y la conducción de la política migratoria del INM, algo que es mucho más amplio que la labor puntual de la captura y el procesamiento internos de los datos estadísticos y ayuda a entender y justipreciar estas labores puntuales de registro.

Antes de pasar a dicho análisis, es pertinente hacer algunas consideraciones sobre los elementos externos en la argumentación oficial. Una consideración que parecería obvia, pero que no lo es tanto, y que resulta pertinente recordar, es que la disminución en el total de migrantes indocumentados detenidos por el INM no es igual a la eventual reducción del flujo transmigratorio. Como lo acepta el INM, hay un porcentaje de migrantes que no es detenido por las autoridades migratorias. Ante ello, el INM estima su número a partir de las detenciones diversas que hacen las autoridades migratorias estadounidenses, más la población centroamericana que se establece en Estados Unidos, según otras fuentes estadísticas de ese país, para llegar a la misma conclusión: reducción del flujo transmigratorio, ratificado de nuevo por fuentes estadísticas de Estados Unidos. Dado que la fortaleza del argumento del InM radica en lo que hacen o dejan de hacer las autoridades migratorias estadounidenses, se tendría que trabajar en un análisis de dichas fuentes. Esa tarea no es el propósito de este escrito, si bien se presentarán unos pocos elementos de análisis para argumentar la necesidad de hacer un estudio a profundidad de dichas fuentes. De cualquier manera, lo que importa en este texto es analizar lo que ocurre en México y lo que hace o deja hacer la autoridad migratoria mexicana.

blicación de dicho instituto que, aunque aclara que las opiniones son exclusivamente de los autores, todos ellos empleados del INM, lo cierto es que distintos funcionarios han reiterado los mismos argumentos e interpretaciones en actividades oficiales. 
GRÁFICA 2

Población nacida en el exterior y residente en Estados Unidos según región de nacimiento, 2000 y 2010.

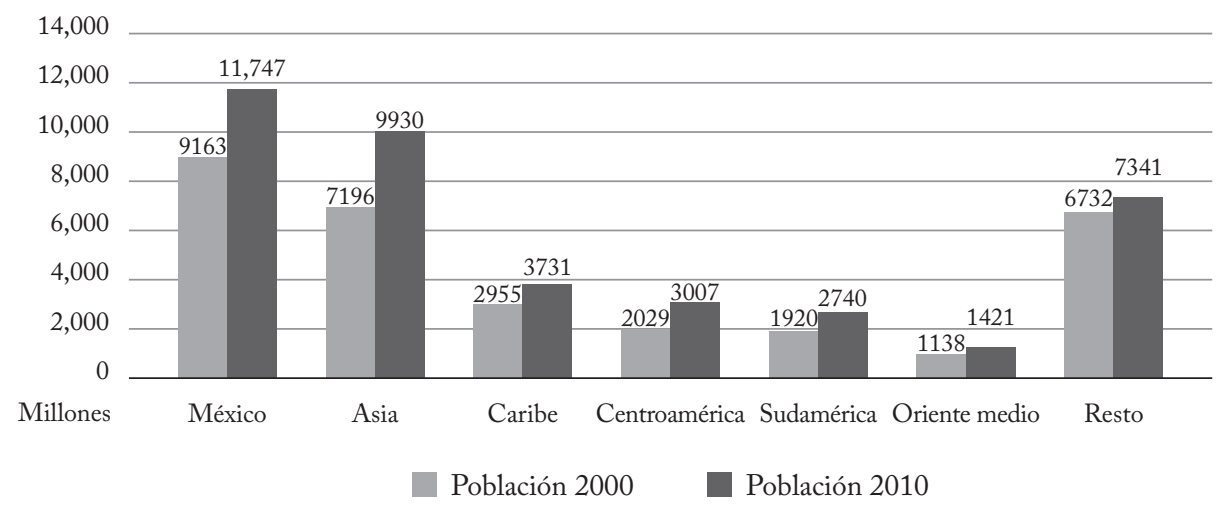

Nota: Oriente medio incluye Afganistán, Irán, Iraq, Israel/Palestina, Jordania, Kuwait, Líbano, Arabia Saudita, Siria, Turquía, Yemen, Argelia, Egipto, Marruecos y Sudán. Fuente: elaboración propia con base en Eileen Patten (2012), «Statistical Portrait of the Foreign-Born Population in the United States, 2010», Pew Hispanic Center, febrero 2012.

La población extranjera que reside en Estados Unidos creció durante el primer decenio del siglo xxi, tal y como lo muestra la gráfica 2.

A primera vista, se observa un incremento de la población para todos los grupos inmigrantes durante el periodo que comprende los años de 2000 a 2010. No obstante, cuando se observa la distribución porcentual de estas mismas cifras en el periodo estudiado (véase la gráfica 3 en la página siguiente), se identifican regularidades que señalan que, a pesar de los incrementos, el peso de algunos grupos de inmigrantes no ha cambiado. Tal es el caso de los inmigrantes mexicanos, cuya participación en el total de la población extranjera residente en Estados Unidos no ha cambiado. La migración de Oriente Medio y el resto de los países ha experimentado un descenso, mientras que las regiones de Asia, el Caribe, Centroamérica y Sudamérica sí experimentaron un ascenso. 


\section{GRÁFICA 3}

Estructura porcentual de la población nacida en el exterior y residente en Estados Unidos según región de nacimiento, 2000 y 2010.

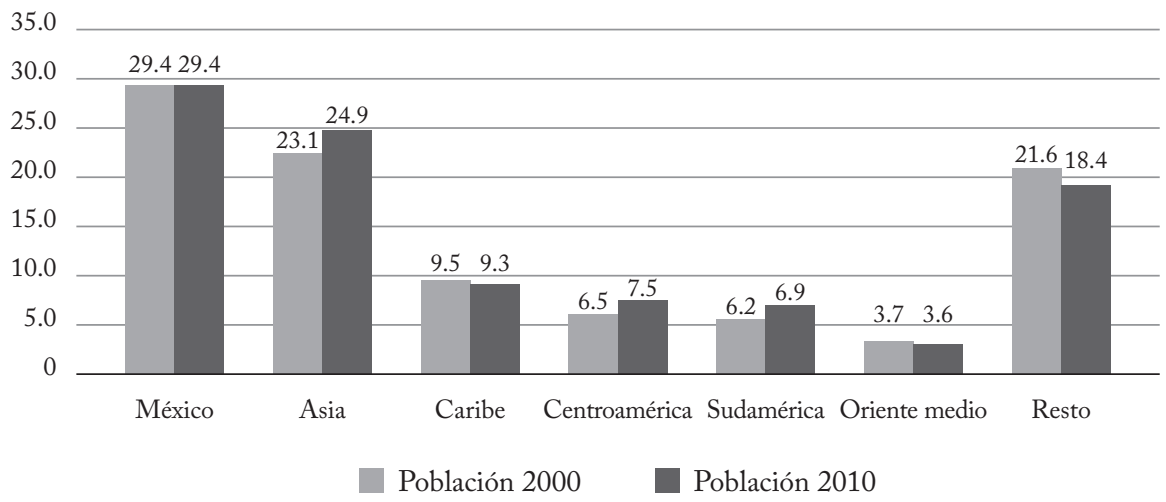

Nota: Oriente Medio incluye a Afganistán, Irán, Iraq, Israel/Palestina, Jordania, Kuwait, Líbano, Arabia Saudita, Siria, Turquía, Yemen, Argelia, Egipto, Marruecos y Sudán. Fuente: elaboración propia con base en Eileen Patten (2012), «Statistical Portrait of the Foreign-Born Population in the United States, 2010», Pew Hispanic Center, febrero 2012.

Estas diferencias son explicadas por algunos analistas, particularmente para México, como resultado de la crisis económica de mediados de 2007. Sin embargo, pareciera que esta situación no se comparte por otros grupos de inmigrantes, como el de los centroamericanos.

Cada flujo centroamericano tiene sus particularidades y comportamientos, en pocas palabras, su historia; algo de ésta se puede ver reflejada en los números plasmados en los registros estadísticos. La heterogeneidad resultante es evidenciada en los cuatro países del norte de Centroamérica, tal y como lo muestra la gráfica 4 de la página siguiente: para El Salvador, 2003 y 2008 son los puntos de inflexión que cambian la dirección de su dinámica migratoria; para Guatemala, 2001 y 2007; para Honduras, 2004, y para Nicaragua, 2001, 2004, 2007 y 2010. Y lo mismo se evidencia en la distribución porcentual, según la gráfica 5 . 
GRÁFICA 4

Población centroamericana residente en Estados Unidos según país de nacimiento, 2000-2010.

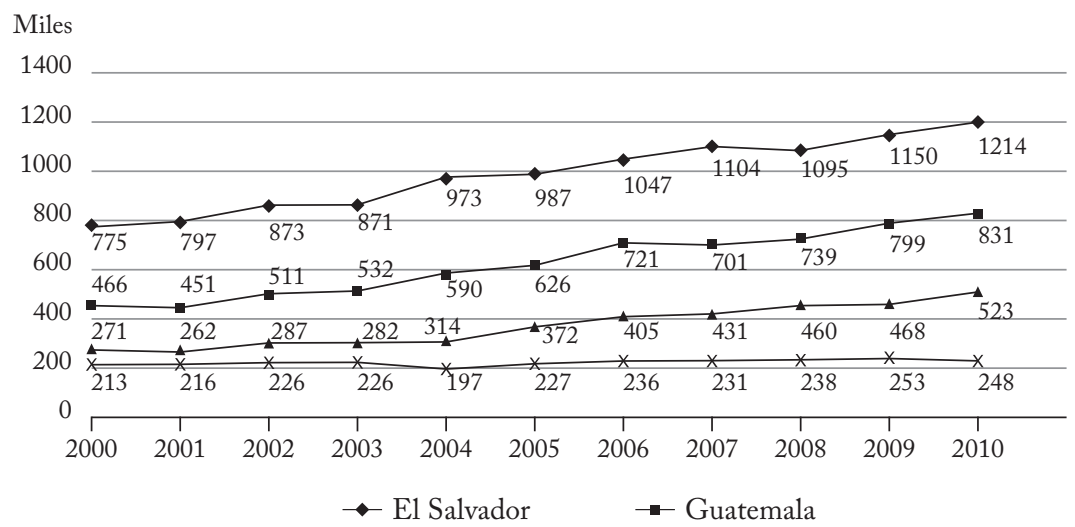

Fuente: elaboración propia con base en Jesús Cervantes (2011), «La población inmigrante de origen latinoamericana en Estados Unidos», documento de trabajo de la Facultad Latinoamericana de Ciencias Sociales, a partir de información de la Encuesta sobre la Comunidad Estadounidense 2000-2010 (American Community Survey) de la Oficina del Censo de Estados Unidos.

Aunque un importante componente de la población centroamericana es indocumentado, hay variaciones en los totales de población que no siguen una tendencia ascendente, como puede ocurrir con otros flujos migratorios internacionales. Esto presupone que, aunque la situación económica de Estados Unidos ha transitado por una época complicada desde el año 2007 que desalentó en algunos casos la migración hacia «el norte», los datos aquí presentados presumiblemente apuntan a que, en el caso de la población centroamericana, la crisis no ha desalentado la migración hacia Estados Unidos, por lo menos desde 2008. Empero, como se verá en los desarrollos por venir, los datos de la economía centroamericana darán otros elementos para el análisis que, combinado con Estados Unidos, Centroamérica y México, no permiten avalar la interpretación del INM sobre la transmigración centroamericana por suelo mexicano. 


\section{GRÁFICA 5}

Población nacida en el exterior y residente en Estados Unidos según región de nacimiento, 2000 y 2010.

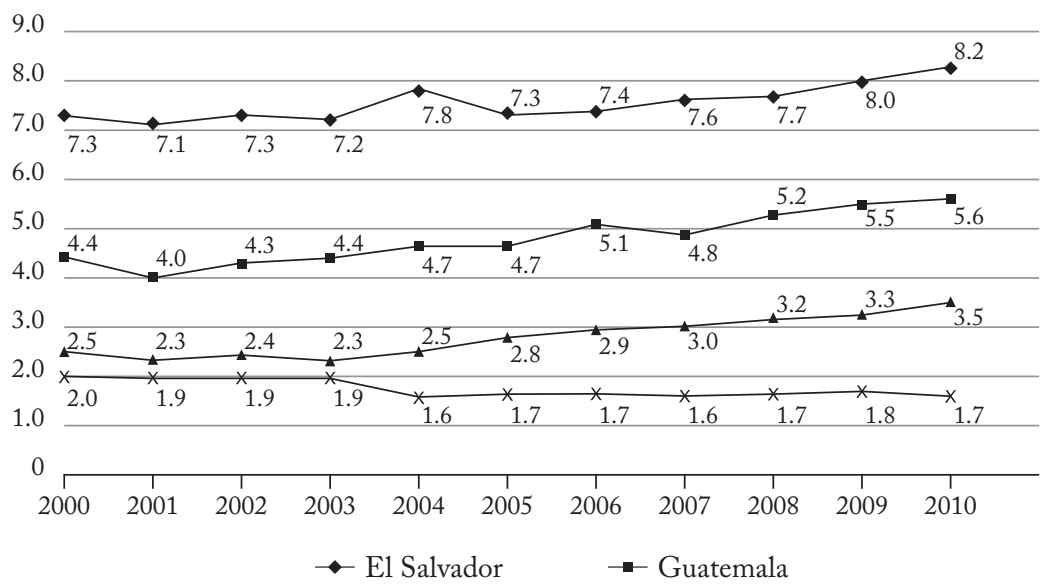

Fuente: elaboración propia con base en Jesús Cervantes (2011), «La población inmigrante de origen latinoamericana en Estados Unidos», documento de trabajo de la Facultad Latinoamericana de Ciencias Sociales, a partir de información de la Encuesta sobre la Comunidad Estadounidense 2000-2010 (American Community Survey) de la Oficina del Censo de Estados Unidos.

Por lo anterior, hay otras consideraciones que hacer. Unas se refieren a la visión de oferta y demanda del mercado laboral, otras a lo que ocurre en los lugares de origen de la migración centroamericana. Por la brevedad, se aborda en primer lugar el mercado.

Se dice que a menor demanda de trabajadores debido a la crisis económica en Estados Unidos, le corresponde una menor oferta de brazos disponibles; que los migrantes se desalientan al no haber trabajo en Estados Unidos y desisten de emigrar. Ese argumento es muy cuestionable. No hay ecuaciones perfectas en los mercados, como tampoco en lo social. Desde un punto de vista teórico, y que se comprueba en los hechos, uno de los elementos que dinamizan los mercados son los desequilibrios: a menor demanda suele ocurrir una oferta mayor, lo que amplía el margen de ganancia. Parte 
fundamental de la racionalidad del mercado es la ampliación del margen de ganancia, y el desequilibrio entre oferta y demanda lo favorece, no el logro del equilibrio entre una y otra. Lo primero, es típico del mercado. La búsqueda de que el desequilibrio no se convierta en problema social debiera ser preocupación del Estado, cosa que no siempre ocurre.

Frente a la crisis económica, por el contrario, se han presentado diversas consecuencias, aunque en este escrito sólo se haga mención de las directamente relacionadas con el flujo transmigratorio: I) eventualmente, un mayor celo migratorio en el país receptor de migrantes, porque una mayor presencia de trabajadores desempleados y de extranjeros se puede convertir en un problema para las autoridades de servicios públicos (salud, por ejemplo) y de seguridad pública; 2) un encarecimiento del tráfico de indocumentados; 3) una contracción de la economía dependiente, como es el caso de la centroamericana, y 4) una mayor presión sobre el trabajador de la economía dependiente para buscar, dentro o fuera de su país, la satisfacción de sus necesidades.

Con un mayor celo en las fronteras, el Estado pretende regular flujos para que no se presenten efectos de desestabilidad para el gobierno, aunque, por otro lado, las fuerzas de mercado procurarán mantenerse atrayentes de más mano de obra para garantizar un amplio stock de trabajadores disponibles que les permita superar la crisis, y una manera de hacerlo es con bajos salarios. Como es de conocimiento general, las fuerzas políticas y regionales, particularmente las fronterizas tipo sun belt, pueden diferenciarse de las disposiciones de la Casa Blanca, para lograr sus objetivos específicos. Dos ejemplos recientes de ese proceder: cuando ocurrieron los atentados del 11 de septiembre de 2001, la disposición federal fue cerrar las fronteras de manera inmediata, una decisión entendible y acatada sin cortapisas por los distintos sectores sociales estadounidenses. Empero, al paso de los días, las presiones fueron en ascenso por parte de grupos comerciantes ubicados a lo largo de la frontera de Estados Unidos con México, pues sus ventas eran inexistentes o ínfimas. Poco a poco, se fueron tomando disposiciones locales para regularizar el comercio, es decir, el ingreso y el tránsito fronterizo que — no hay que olvidarlo— se estima que 
puede llegar a ser de un millón de cruces al día. Un segundo ejemplo: pareciera que las autoridades estadounidenses son de alta efectividad para detener a indocumentados que pretenden ingresar a Estados Unidos, aunque resulta inexplicable que esas mismas autoridades de seguridad interna, con amplísimo despliegue de personal y tecnología de punta, sean incapaces de detectar el impresionante tráfico ilegal de armas procedentes de Estados Unidos y destinadas a México; un tráfico de armamento que reiteradamente denunció el propio ex presidente de México, Felipe Calderón, de manera infructuosa. ¿Pueden ver todo lo que va del sur al norte, pero no ven lo que va del norte al sur? ¿Cómo no dudar de su rectitud, cómo confiar en que sus datos están exentos de algún tipo de manipulación? ¿Cómo, entonces, respaldar el argumento del INM en algo que no presenta garantía de confiabilidad?

Las fuentes internacionales coinciden en señalar la situación crítica de las economías centroamericanas (aunque no lo incorporen en su análisis las voces gubernamentales de México), lo cual llevaría a pensar que los flujos migratorios centroamericanos no se contraen, ${ }^{3}$ tampoco van de manera significativa a nuevos destinos, ${ }^{4}$ sino que se incrementan o, en el peor de los casos, se mantienen constantes, más allá de una posible reducción menor a un par de años.

Si a ello se agregan elementos políticos, como la remoción presidencial, en 2009, en Honduras, la creciente inseguridad pública (E1 Salvador) o los cambios gubernamentales (Honduras Guatemala, Nicaragua y El Salvador), la estabilidad económica y política y la seguridad pública no son los rasgos dis-

${ }^{13 /}$ Por una mejora salarial o por la generación de nuevos empleos, que no ocurren. Por el contrario, la situación se ha deteriorado.

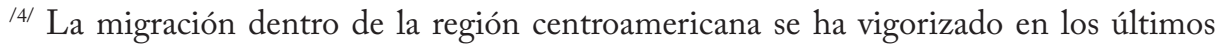
años, pero no al grado de constituirse como una nueva opción para los flujos que tienen como proyecto llegar a Estados Unidos. Los centroamericanos no migran al sur del continente. Es muy complicado que puedan cruzar las puertas de Europa occidental, y México aún dista de ser un destino consolidado, así sea que poco a poco se vaya observando una presencia paulatinamente mayor de quienes se quedan en el camino. 
tintivos de la región centroamericana. De ser así, entonces se podría plantear, razonablemente, la hipótesis de que a la caída en el registro gubernamental de detenciones de indocumentados en México ha correspondido una estabilidad en el flujo de transmigrantes, si no es que un incremento del mismo, aunque ocurra para los mismos años una baja en el registro estadístico del INM, lo cual se debe a otras razones que se exponen en lo que sigue de este texto.

\section{CUADRO 3}

Indicadores económicos Guatemala, El Salvador, Honduras y México, 2000, 2005 y 2010. Porcentajes.

\begin{tabular}{|c|c|c|c|c|}
\hline PAís/AÑo & DÉFICIT COMERCIAL & INFLACIÓN" & Población ${ }^{*}$ & Desempleo \\
\hline \multicolumn{5}{|c|}{ Guatemala } \\
\hline 2000 & 6.103 & 9.079 & 11.225 & n.d. \\
\hline 2005 & 4.559 & 8.567 & 12.701 & n.d. \\
\hline $2010^{*}$ & 2.908 & 5.485 & 14.362 & n.d. \\
\hline \multicolumn{5}{|c|}{ El SAlVAdor } \\
\hline 2000 & 3.02 & 4.288 & 5.474 & 6.94 \\
\hline 2005 & 3.545 & 4.261 & 5.666 & 7.23 \\
\hline $2010^{*}$ & 2.775 & 1.5 & 5.864 & 6.628 \\
\hline \multicolumn{5}{|c|}{ Honduras } \\
\hline 2000 & 7.096 & 10.1 & 6.23 & 4 \\
\hline 2005 & 2.988 & 7.748 & 6.893 & 4 \\
\hline $2010^{*}$ & 6.284 & 5.7 & 7.614 & 4.6 \\
\hline \multicolumn{5}{|c|}{ MÉXICO } \\
\hline 2000 & 2.971 & 8.869 & 97.966 & 2.2 \\
\hline 2005 & 0.536 & 3.287 & 103.946 & 3.579 \\
\hline $2010^{*}$ & 1.159 & 4.5 & 108.627 & 5 \\
\hline
\end{tabular}

Fuente: Fondo Monetario Internacional «World Economic Outlook». a/ Déficit comercial como parte del pib. b/ Tasa de variación anual del índice de precios al consumidor. c/ Personas en millones. d/ Porcentaje de la población desocupada de la población económicamente activa. e/ Estimaciones. 
La explicación más plausible, entonces, es que ocurre una transmigración centroamericana (también de otras nacionalidades) ${ }^{5}$ que no deja registro en las estadísticas oficiales de México.

Antes de pasar a lo que ocurre con la política migratoria de México, revisemos algunos indicadores del momento crítico por el que pasan los países centroamericanos, y que alientan la transmigración: el comportamiento del Producto Interno Bruto (PIB), la inversión extranjera directa (IED), las exportaciones, las remesas, la industria maquiladora, el empleo y el desempleo. El pib general y por habitante descendió en todos los países de la región centroamericana. El caso extremo es El Salvador, cuyo crecimiento en 2007 fue de $4.3 \%$ y en 2009 de $-3.5 \%$, mientras que el PIB por habitante fue de $-4 \%$. Honduras registró una tasa de crecimiento de $6.3 \%$ previo a la crisis y en 2009 bajó a $-1.9 \%$, siendo más pronunciada la caída en el PIв por habitante, que fue de $-3.8 \%$. Guatemala fue quizá el país menos afectado: de un crecimiento de $6.3 \%$ en 2007 pasó a $0.5 \%$ en 2009, aunque a nivel de PIB per capita se sitúo para este año en $-2 \%$.

Entre 2007 y 2009, la IED se desplomó en 40\% en la región. El Salvador y Honduras resultaron ser los países más afectados, con caídas respectivas de $71.4 \%$ y $43.6 \%$. Habría que recordar que sus economías acusan mayor dependencia con Estados Unidos. La caída en la IED se tradujo en el cierre de establecimientos y en el incremento del número de desempleados, sobre todo en el sector de la industria maquiladora.

Hoy, las remesas familiares se encuentran por arriba de los montos de la IED, algo que ya se veía previamente a la crisis, cuando la IED alcanza en 2007 la cifra histórica de 5,458.7 millones de dólares, mientras que las remesas familiares suman 11,124.6 millones de dólares. Entre 2007 y 2008, las remesas experimentaron un incremento de 5\%; sin embargo, entre 2008 y 2009 se produjo una caída del orden de $9.74 \%$. En términos absolutos, la

${ }^{15 /}$ Véase, del autor de este texto, Asiáticos y africanos en el México del siglo XXI (en prensa).

$46 \triangleleft$ MIGRACIÓN Y DESARROLLO, VOL. 10, NÚM. 19, SEGUNDO SEMESTRE DE 2012 
región dejó de recibir 1139 millones de dólares en 2009, cantidad que rebasa el monto de las remesas que recibió Nicaragua en 2008. En 2010, las remesas crecieron en 3.4\%; no obstante, no se logra registrar el monto de 2008.

Por la contracción en la demanda en Estados Unidos y la caída de la IED, las exportaciones de bienes de la región centroamericana sufrieron una reducción de $11.3 \%$ en 2009. La mayor caída se registró en la industria manufacturera, siendo la maquila de un peso significativo. Honduras tuvo la mayor caída en sus exportaciones, con 21\%; las de El Salvador cayeron 16.26\%; las de Guatemala, 6.5\% y las de Nicaragua 5.9\%. Entre 1994 y 2005, el número de empresas maquiladoras en Honduras creció en un 75\%, al pasar de 175 a 306 empresas, mientras que el número de personas empleadas se incrementó en casi 200\% (pasó de 42,541 a 125,825 personas empleadas). En 2007 se reportaron 342 empresas y, en 2009, 299 empresas. Para 2007, la rama textil dominaba el comercio exterior de Honduras, el valor de las exportaciones de prendas de vestir y tejidos de punto sumaron 2,550.8 millones de dólares, suma equivalente al $44.1 \%$ de la exportación total de bienes. En El Salvador, entre 1995 y 2000, el número de empresas se mantuvo en el mismo nivel. La maquila contribuyó al desarrollo de la industria manufacturera y pasó de 1.7\% en 1990 al 13.3\% en 2001. En el mismo periodo, su aporte al PIв pasó del 0.4 al 3.1\%.

El hecho de que estas economías tengan una alta dependencia del mercado estadounidense explica el fuerte impacto de la crisis. Pese a una tendencia a disminuir la participación relativa de la maquila en las exportaciones hacia Estados Unidos en 2008, ya en plena crisis, El Salvador, Honduras y Nicaragua registraron altos porcentajes que oscilan entre 69 y $55 \%$; el menor de ellos se registra en Guatemala con poco más de 40\%. En general, la industria maquiladora tiene un peso significativo en las exportaciones totales en los países de la región; en Honduras representan el 55\%, en Nicaragua rebasan $40 \%$ y en E1 Salvador y Guatemala se encuentran por arriba de 35\% del valor de los bienes exportados. En el caso de Honduras, la crisis impactó de manera significativa en el empleo en la industria maquiladora; entre 2007 y 2009 se perdieron 27,312 puestos de trabajo. 
La crisis económica en Centroamérica elevó los índices de desempleo, subempleo y precarización laboral. En 2008 y 2009 se registraron las mayores caídas en el número de empleos. Entre 2007 y 2009, el desempleo creció en Nicaragua en 38\%. La Comisión Económica para América Latina y el Caribe (CEPAL) considera que, para 2006, la pobreza en Guatemala alcanzó al 54.6\% de la población, mientras que la incidencia de la indigencia en ese año fue de 29.1\%. La situación es más grave en el medio rural, pues en 2006 la pobreza permanecía en $70.5 \%$. Para el caso de Honduras, la CEPAL documentó que la incidencia de la pobreza en la población fue de $68.9 \%$ y, en indigencia, de 45.6\% para 2007. En El Salvador, la pobreza en 2009 afectó al 47.9\% de la población y la indigencia al 17.3\%, un poco menos que en Honduras.

En síntesis, la crisis económica en Estados Unidos dio un fuerte coletazo a las economías centroamericanas. La transmigración significó la oportunidad de enfrentar la crisis en los países centroamericanos. Los problemas viejos y nuevos para llegar a Estados Unidos (más inseguridad en el camino, costos más altos para la transmigración, mayores dificultades para obtener empleo en el lugar de destino y menos posibilidades de encontrar salarios dignos) eran la otra cara de la moneda. La adversidad mayor era quedarse a esperar, pero ¿por cuánto tiempo? Mejor correr el riesgo de migrar, pues si algo sabe el marginado de la vida institucional y sus posibles beneficios es vivir en el riesgo constante.

\section{EL INM Y SU PROBLEMÁTICA INTERNA}

Es indudable que del contenido de política migratoria, de su aplicación y del tipo de liderazgo de las autoridades correspondientes habrá resultados que se plasmen en registros estadísticos, como el total de extranjeros indocumentados detenidos. Desde esa lógica, existen procesos y decisiones que inciden en la reducción numérica de los flujos migratorios detenidos por el INM. Analicemos. 
Aceptando, sin conceder, que las cifras sobre detención de indocumentados pudieran ser ciertas, pueden ser analizadas en el contexto en que se elaboran los registros. Como se mostró en el cuadro 2, durante 2001, la administración de Vicente Fox reportó 150,530 eventos de indocumentados detenidos por Migración. Para 2005, la cifra llegó a 240,269. En 2006, disminuye a 182,705, llega a su punto más bajo en 2008 con 39,436, y para 2009 y 2010 presenta cifras al alza, casi similares, de poco más de 69 mil por año. Los argumentos que tratan de explicar la reducción carecen de rigor histórico, así sea que las fechas sean cercanas en el tiempo. En efecto, hacen referencia a lo ocurrido entre 2006 y el presente en los siguientes términos: I) es una combinación de política exitosa de contención y expulsión de Estados Unidos, y 2) el desaliento entre migrantes por la crisis económica en ese país. Prácticamente, nada se dice de la política migratoria mexicana; por omisión, pareciera que ésta es inequívoca, justo en los tiempos en que los daños a la integridad física de los migrantes centroamericanos, en particular, son de la mayor gravedad.

En primer lugar, resulta pertinente analizar nombramientos, así como el proceder de las autoridades migratorias y las disposiciones administrativas internas. Del perfil de las autoridades, de su conocimiento o no en materia migratoria y de su actuación resulta una política específica, con mayor o menor apego a las disposiciones legales correspondientes.

De agosto de 2005 a diciembre de 2006 fueron nombrados cuatro titulares en el inм. ${ }^{6}$ Salvo uno que había desempeñado previamente puestos de mando medio en el INM, todos los demás carecían de trayectoria en la conducción política migratoria; incluso, hubo quien vivía su primera incursión profe-

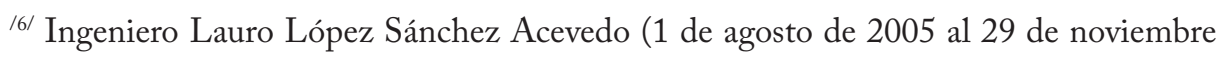
de 2005); ingeniero Pablo Enrique Torres Salmerón (30 de noviembre de 2005 al 16 de abril de 2006); licenciado Hipólito Treviño Lecea (17 de abril de 2006 al 7 de diciembre de 2006); licenciada Cecilia Romero Castillo (8 de diciembre de 2006 al 14 de septiembre de 2010). 
sional en el ámbito del Poder Ejecutivo. A los cambios en la titularidad del INM siguieron cambios en las coordinaciones - la instancia más cercana al titular de acuerdo al organigrama de la dependencia-, de delegados en entidades federativas y reacomodos en algunas de ellas. Con estas referencias de cambios, inestabilidad, iniciación gubernamental en el mando federal de migración, en cuadros de dirección intermedia y responsables en los estados es más factible encontrar una explicación en la caída en las estadísticas gubernamentales que a causales macroeconómicas. Fue justamente en 2006, con tanto cambio directivo, cuando se inicia la caída en el total de indocumentados detenidos, descenso en el registro que llegaría a su punto más bajo en 2008. Fueron tres años de «caída libre» que, para quien conozca de instituciones operativas de gobierno, y más de la complejidad del INM, sabrá del peso significativo de la conducción institucional competente en los resultados y la manera de obtenerlos.

La crisis económica inició en el segundo semestre de 2008 y sería asombrosa la sincronía entre ese evento y la caída del flujo de migrantes para ese año. Para 2009 y 2010, la tendencia al alza en detenciones por el INM casi duplicaba la cifra de 2008, cuando era esperable observar los supuestos efectos de desaliento en los indocumentados por la crisis. Por el contrario, ese nuevo incremento en el total de indocumentados detenidos pareciera responder a los efectos de la crisis económica de Estados Unidos en Centroamérica con un nuevo aliento a la transmigración. Esa alza podría, incluso, marcar el reinicio de la tendencia al alza del flujo (si la mayor detención fuera reflejo cercano del engrosamiento del flujo) y no el inicio de una tendencia en la disminución de la transmigración centroamericana.

En 2005 y 2006 hubo desastres naturales que afectaron el sur-sureste mexicano: crecidas de ríos e inundaciones que, entre otras cosas, alteraron las rutas migratorias. El INM tuvo a bien suspender, temporalmente, los operativos de detención de indocumentados. En 2005, por efectos de las inundaciones, desapareció, literalmente, la estación del tren en Tapachula, que era de donde partía el grueso de la transmigración que se trasladaba en tren. A partir de entonces, la ciudad de Arriaga, en el norte de Chiapas, ubicada aproxi- 
madamente a 300 kilómetros de Tapachula, se convirtió en el nuevo lugar de salida, ya en territorio mexicano, de los flujos transmigratorios que optaban por esa vía de traslado. El inm no abrió una oficina en Arriaga ni destinó más personal; tampoco realizó más operativos en Arriaga, sino que siguió enviando unos cuantos elementos desde Tapachula hacia el nuevo sitio. Es innegable que esta situación tuvo, al menos, dos repercusiones: r) hubo un ajuste en las rutas migratorias, mismo que fue aprovechado por los traficantes de migrantes y por las redes delictivas que ya para ese entonces veían en los migrantes un nuevo nicho de su mercado, aunque de eso no se percataran las autoridades gubernamentales de México, y 2) la delegación del inM en Oaxaca esperó a captar el flujo engrosado. Esto trajo como consecuencia, como luego lo documentaría la Comisión Nacional de los Derechos Humanos ( $\mathrm{CNDH}$ ), que, por un lado, se registrara un auge en el secuestro masivo de migrantes (CNDH, 2009) y que, por el otro, las autoridades empezaran a tener una recurrente confrontación con las instancias humanitarias, en particular las de Oaxaca (Brito, 23 de julio de 2011, Milenio).?

En 2009, a raíz del surgimiento del nuevo virus de influenza AH IN I, el INM volvió a suspender temporalmente, durante el segundo trimestre del año, la detención de migrantes indocumentados por los riesgos de contagio en las estaciones migratorias, justo cuando los efectos de la crisis de 2008

${ }^{17 /}$ Los momentos de tensión y conflicto entre autoridades migratorias e Iglesia católica, sin embargo, no se limitaron a lo ocurrido en Oaxaca; en efecto, el arzobispo Rafael Romo, responsable de la Dimensión Pastoral de la Movilidad Humana (Dрмн) del Episcopado Mexicano, que es la instancia eclesial que se ocupa del tema migratorio, señaló de manera unívoca en conferencia de prensa en el Senado de México: «La falta de atención oportuna a la violencia e inseguridad ha generado que se elevara el número de ataques de 18 incidentes de riesgo en cinco años — 2004 a 2009- a 46 en año y medio — 29 en 2010 y 17 en 2011—, siendo el principal agente persecutorio o agresor el mismo Estado, a través de funcionarios públicos de los tres niveles de gobierno que intentan intimidarnos para que no denunciemos abusos y violaciones de derechos humanos que cometen contra migrantes».

MIGRACIÓN Y DESARROLLO, VOL. 10, NÚM. 19, SEGUNDO SEMESTRE DE 2012 51 
hubieran sido más visibles entre los indocumentados en los términos negativos que se argumenta desde el INM; en caso contrario, la cifra de detenciones hubiera sido mayor.

A estos hechos hay que agregar las disposiciones de repliegue de la autoridad de los espacios sociales de la migración, con consecuencias de suma gravedad, en tanto que el retiro de la autoridad de los espacios dinámicos de la migración indocumentada facilitó, y dejó impune, la acción delictiva de secuestros masivos de migrantes, además de que no detuvo a migrantes indocumentados en tránsito.

Mediante disposiciones administrativas internas del INM y nugatorias de colaboración o coadyuvancia interinstitucional, se limitó o negó la participación de otras dependencias públicas, lo que redundó en un incremento de facultades discrecionales de funcionarios del inм y en la liberación de personas físicas que institucionalmente tenían que ver con la migración (así tuvieran un proceder equívoco e ilegal). También se acotó o negó la participación de instituciones, pero se dejó en libertad a los servidores públicos que, manteniéndose presentes en el medio migratorio, continuaron con sus relaciones interpersonales en el medio laboral, ahora fuera de un posible control institucional. Adicionalmente, por instrucciones superiores del INM, el personal del propio instituto dejó de realizar operativos dentro de los albergues y las casas de migrantes, que podían realizar según el mandato legal de 2007 en adelante. En los hechos, todo esto se tradujo en facilidades para el tráfico de indocumentados, así como el de documentados (los llamados «pollos empapelados»), además de condiciones favorables para la colaboración de distintas redes de tráfico de migrantes, con secuelas negativas como las de San Fernando (Casillas, 2010). Las medidas concretas fueron las siguientes:

I) Que el personal del INm podría aprobar el ingreso y la estadía de extranjeros en México, incluso desechando la negativa argumentada del cónsul mexicano que entrevistara al solicitante de visa. Ése fue un caso recurrente que causó molestias entre el personal del servicio exterior y preocupación entre las ins- 
tancias de seguridad nacional, pero que se llevó adelante por la cercanía de la comisionada del INM con funcionarios del más alto nivel del Ejecutivo federal.

2) Que se dejaran de hacer operativos en trenes y carreteras (volantas), lo que facilitó el tráfico de indocumentados; esto respondió a instrucciones superiores del INM, particularmente de la entonces comisionada. Es importante hacer notar que la Coordinación de Verificación y Control Migratorio tiene, desde hace varios años, un registro en que asienta, según las características de cada delegación, un movimiento diario, semanal o mensual de los operativos que realiza en las redes carreteras y ferroviaria, así como de inspección en inmuebles y en los lugares donde se realizan los operativos móviles. Dicho de otra manera, un análisis de esa fuente interna bien le podría dar elementos al propio INM de las implicaciones de disminuir el número de operativos, así como de realizarlos o no en lugares estratégicos para el tránsito migratorio. Empero, ese análisis no fue hecho, aunque, mientras esa fuente exista, es posible hacerlo.

La cercanía religiosa de la entonces titular del INM con la Iglesia católica no sólo evitó que las casas de migrantes ${ }^{8}$ — casi todas de filiación católicafueran sujetas a revisión migratoria, sino que además propició que agentes de la pastoral tuvieran una injerencia activa en los procesos de atención y desahogo de entrevistas a algunas de las probables víctimas de delitos al interior del propio INM. Por la vía de los hechos, se inició una política pragmática de colaboración con organismos religiosos que, como posible propósito de transparencia en la gestión pública, no es criticable; empero, desde un punto de vista legal, ese proceder era improcedente, por no decir ilegal. Faltó creatividad para iniciar una colaboración benéfica entre dependencias de gobierno e instancias civiles,

18/ Véase del autor de este texto, «La labor humanitaria y los organismos civiles: la experiencia de los albergues y casas de migrantes, realidades y desafíos», en Leonir M. Chiarello (coordinador) (2011), Las políticas públicas sobre migraciones y la sociedad civil en América Latina. Los casos de Argentina, Brasil, Colombia y México, New York, Scalabrini International Migration Network. 
se trastocó la ley y se prefirió un arreglo privado con una iglesia en particular, aunque cabe precisar que ese acuerdo privado no se convino con los responsables de los albergues, independientemente de si eran laicos o de su adscripción al clero regular o secular, sino con la jerarquía eclesial.

Esas medidas, junto con otras para retirar de labores de coadyuvancia con el INM a las instituciones de seguridad pública —el Ejército y la Marina-, dadas las evidencias de que miembros de esas agrupaciones habían cometido abusos y violaciones a los derechos humanos de los migrantes, se traducirían, presumiblemente, en una disminución de daños al migrante, pero ocurrió exactamente lo contrario, pues lo que se necesitaba no era ausentar a la autoridad de los espacios dinámicos de la migración, sino perfeccionar su presencia y los mecanismos de colaboración entre autoridades y organismos humanitarios. Se tomaron iniciativas que se podría pensar que eran de buena fe, así fueran ilegales, en un medio en que privaba la emergencia ante la actuación de organismos delictivos, quienes se han caracterizado, justamente, por la ausencia de buena fe. En consecuencia, hubo incremento en los delitos en contra de los transmigrantes y un decremento en el número de transmigrantes detenidos por el INM.

Al quedar exentos de una presencia (así fuera distante) de los agentes del INM o de cualquier otra autoridad (legal, así fuera ocasional), los albergues y las casas de migrantes se convirtieron en nichos privilegiados para cualquier persona u organización que quisiera infiltrarlos conforme a sus intereses más diversos: ${ }^{9}$ desde agentes locales de seguridad (personas físicas) con propósitos aviesos, traficantes de personas con la intención de enganchar

19/ La nueva Ley de Migración, aprobada en mayo de 2011, no evita esos riesgos, pues de manera expresa prohíbe el ingreso de la autoridad migratoria en casas y albergues de migrantes. En efecto, la única novedad que presenta al respecto es un incremento en las sanciones económicas y en castigos para quienes delinquen de esta manera, lo que resulta a todas luces insuficiente dada la complejidad de los procesos delictivos involucrados que, por otra parte, ni siquiera son considerados.

544 MIGRACIÓN Y DESARROLLO, VOL. 10, NÚM. 19, SEGUNDO SEMESTRE DE 2012 
migrantes, o con la intención de que «sus» migrantes descansaran a costa de la organización que les albergara, hasta enviados de secuestradores de migrantes. A lo más que puede llegar el personal de los albergues es a expulsar al agente avieso, es así que la impunidad ha quedado garantizada desde ese entonces. Esta dinámica ayuda a explicar el porqué también hay una reducción en los registros de migrantes en los albergues: por el miedo del migrante a ser detectado en los albergues y ser secuestrado al salir de ellos.

\section{GRÁFICA 6}

Expedición de formas migratorias de visitante local 2005-2010.

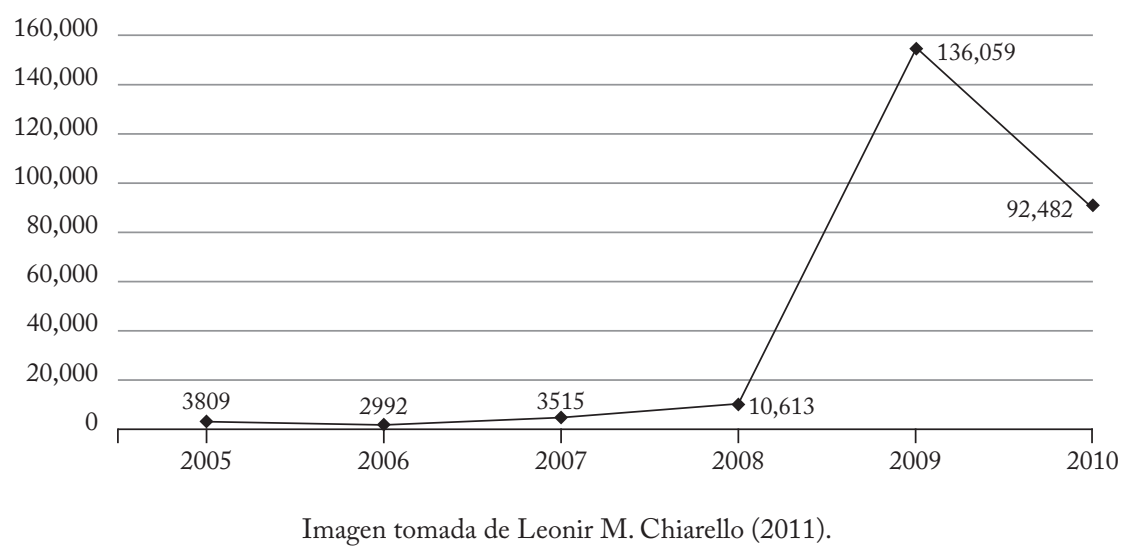

El INM, por otra parte, realizó algunas modificaciones importantes para el otorgamiento de visas o permisos de trabajo en la región fronteriza del sur. Esa labor es encomiable porque no sólo nutre los registros administrativos sino también porque amplía la cobertura legal a trabajadores diversos, así como el espacio territorial y el número de entradas. Para su realización, y durante el tiempo que fue necesario, las delegaciones involucradas, en particular la de Chiapas, contaron para tal efecto con su personal ordinario; ello quiere decir que parte del personal asignado a otras funciones, por ejemplo, a la realización de los operativos móviles, fue comisionada para el levantamiento 
del registro correspondiente. Como se puede ver en las gráficas 6 y 7 y en el mapa 1, esta situación coincide con la baja en el registro de detenidos; sin embargo, es importante considerar que al mismo tiemopo se incrementó el número de migrantes regularizados.

MAPA I

Cobertura geográfica de la forma migratoria del visitante local.

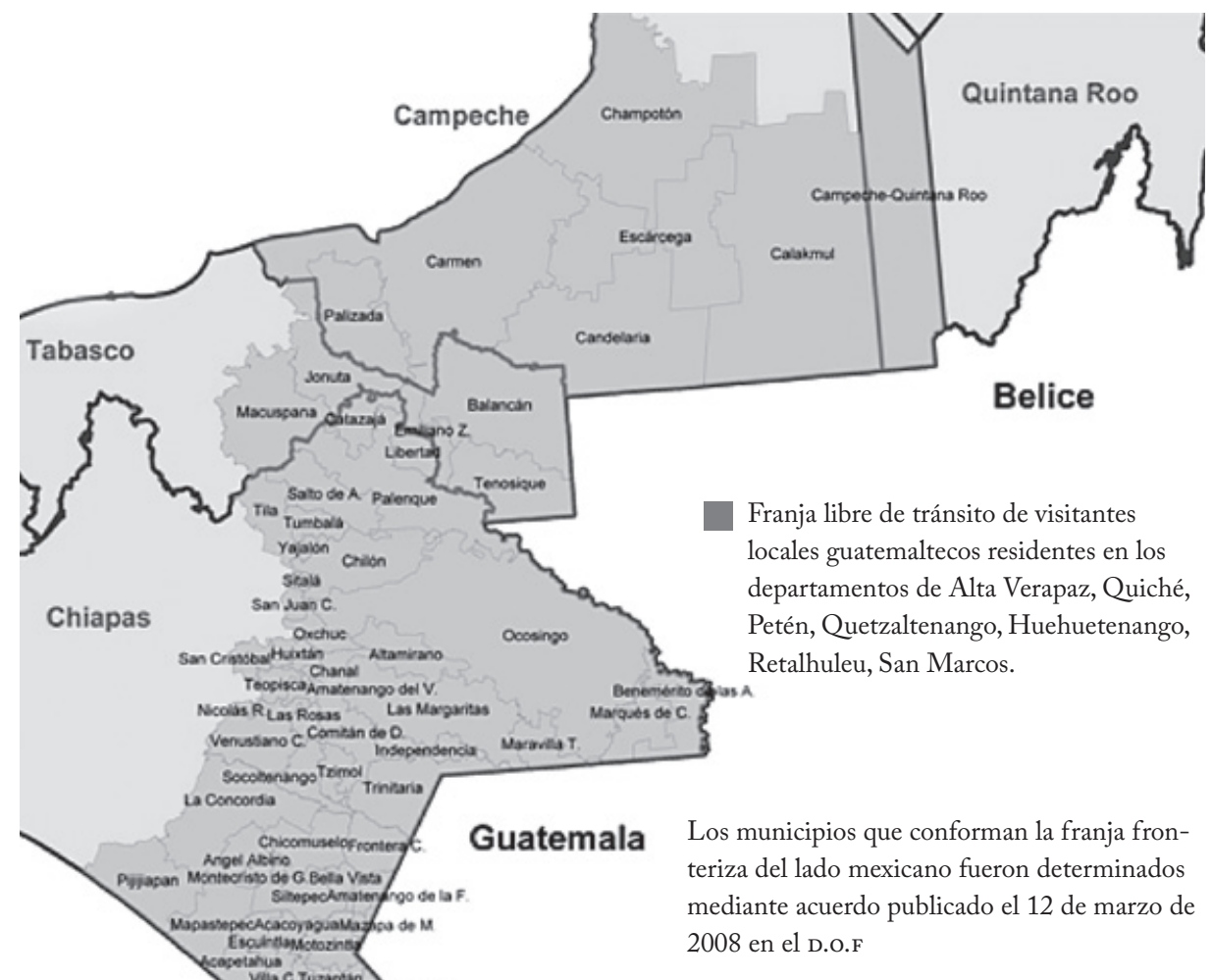

Fuente: Centro de Estudios Migratorios, InM 2008

Imagen tomada de Leonir M. Chiarello (2011). 
GRÁFICA 7

Expedición de formas migratorias de trabajador fronterizo 2005-2010.

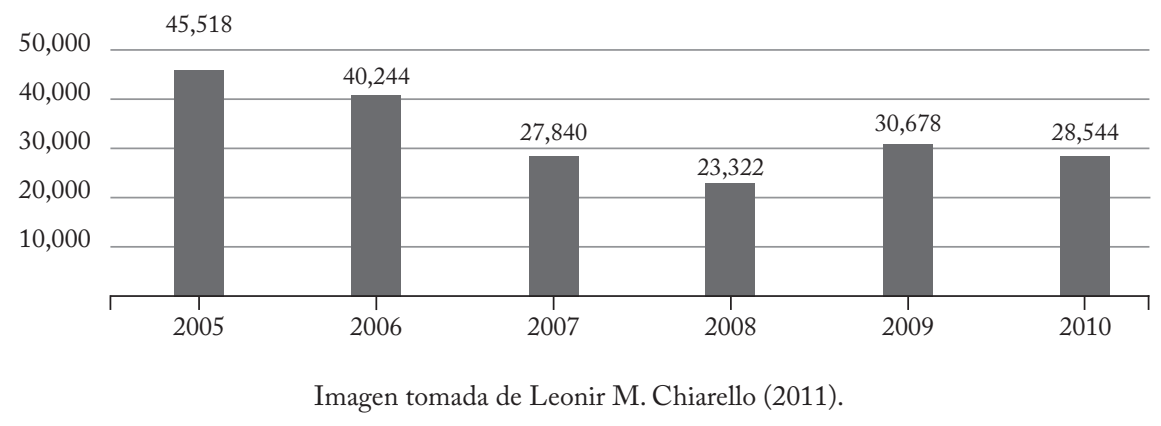

En síntesis, la caída en las cifras de migrantes en el INM y en albergues puede responder a un proceso real, pero las razones de esas disminuciones son distintas y, en cierto sentido, complementarias. No ha quedado demostrado, sin embargo, que dicha disminución general en registros gubernamentales y organismos humanitarios responda a una contracción de la transmigración de acuerdo con lo argüido por el INM. En consonancia con lo que se ha expuesto hasta aquí, es recomendable hacer un análisis mucho más cuidadoso e incluyente de los elementos internos dejados fuera del análisis oficial — como el que se ha propuesto en este trabajo- y del porqué hay una reducción en las cifras del InM. Para poder profundizar en este análisis sería necesario, por ejemplo, que el inM diera a conocer la metodología que utiliza en la construcción de sus datos estadísticos, que fuera de conocimiento público lo relativo a los operativos móviles realizados, al personal por delegación y partícipes en operativos, etcétera. ${ }^{10}$ De otra manera, justipreciar contenido y alcance es tarea compleja que cuestiona profundamente lo parcial e incompleto del dato oficial, más

${ }^{110 /}$ Es previsible que se argumente que el INM no puede dar a conocer ese tipo de información por motivos de seguridad, dado que se alertaría a las redes delictivas del modus 
cuando se toman en cuenta los elementos de juicio aquí vertidos, que son absolutamente verificables y que, por alguna razón no dicha, el propio INM omite en su análisis y explicación del proceso transmigratorio.

\section{¿Seguimos como vamos o CAmbiamos?}

Por lo antes expuesto, hay serias y fundadas dudas sobre la veracidad de los datos del INM, que indican una disminución del flujo transmigratorio detenido por la autoridad mexicana, y que pareciera presentar la versión oficial como sinónimo del comportamiento del flujo indocumentado, algo lejano a la realidad. Ciertamente, hay una disminución en el registro gubernamental, pero las razones que lo explican son otras y muy diversas a las señaladas por el InM. Dados los argumentos presentados, es claro que el propio INM no está en posibilidades de estimar la disminución real de sus registros, pues para hacerlo tendría que hacer acopio, análisis y valoraciones de los distintos aspectos de política migratoria que hasta el momento ha dejado fuera en sus considerandos. Ojalá lo hiciera por salud institucional y porque ayudaría a entender

operandi institucional. No se descarta que la delincuencia, que incluye a personal de "cuello blanco", consulte documentos y se prepare para sus acciones, como lo hace de manera prioritaria, hasta ahora, con los «pollos empapelados». Sin embargo, de acuerdo con la experiencia en campo acumulada durante años por el autor de este texto, mucha de esa información empírica llega con oportunidad a quienes delinquen, sin necesidad de hacer consultas a fuentes públicas sistematizadas; dicho de otra manera, tal y como están actualmente las cosas, aparte del personal gubernamental con competencia en la materia, quienes tienen acceso, obviamente sin que se les finque algún tipo de responsabilidad, son quienes delinquen con los migrantes. Así, y sin que sea propósito consciente, se favorecen los desequilibrios que vulneran a personas e instituciones y se limita la participación fundada de analistas, de organismos que realizan labores humanitarias y de quienes desde distintos frentes procuran contribuir a una mejor política migratoria nacional y, a final de cuentas, a una mejor sociedad. 
mejor los gravísimos daños a los migrantes, a la vida institucional y a los tejidos sociales específicos que de distinta manera están vinculados con los procesos migratorios que ocurren en el país. Para generar una nueva política migratoria, tan urgentemente necesaria en México, que recupere lo rescatable de lo hecho y construido, se requiere un análisis introspectivo a fondo, sin distorsiones ni encubrimientos. Pero para ello, aparte de capacidad, recursos técnicos y apertura en el análisis, se requiere voluntad política, vigorosa y sostenida por todo el tiempo que sea necesario, y pareciera que también de eso anda escaso México en sus instancias de mando gubernamental.

\section{RefERencias}

Brito, Omar (23 de julio de 2011), “"Gobiernos, los agresores” de activistas pro migrantes», Milenio, http://www.milenio.com/cdb/doc/impreso/8996746>.

Casillas, Rodolfo (en prensa), Asiáticos y africanos en el México del siglo XXI, México.

(2011), «La labor humanitaria y los organismos civiles: la experiencia de los albergues y casas de migrantes, realidades y desafíos», en Leonir M. Chiarello (coordinador), Las politicas públicas sobre migraciones y la sociedad civil en América Latina. Los casos de Argentina, Brasil, Colombia y México, Nueva York, Scalabrini International Migration Network.

(2010), «Masacre de transmigrantes», Foreign Affairs Latinoamérica, vol. 10, núm. 4.

Cervantes, Jesús (2011), «La población inmigrante de origen latinoamericana en Estados Unidos», documento de trabajo de la Facultad Latinoamericana de Ciencias Sociales, a partir de información de la Encuesta sobre la Comunidad Estadounidense 2000-2010 (ACs) de la Oficina del Censo de Estados Unidos.

Chiarello, Leonir M. (coordinador) (2011), Las políticas públicas sobre mi- 
graciones y la sociedad civil en América Latina. Los casos de Argentina, Brasil, Colombia y México, New York, Scalabrini International Migration Network.

CNDH (2009), Informe especial de la Comisión Nacional de los Derechos Humanos sobre el caso de secuestro en contra de migrantes, México, CNDH.

Pattern, Eileen (2012), Statistical Portrait of the Foreign-Born Population in the United States, 2010, Washington, Pew Hispanic Center.

Rodríguez Chávez, Ernesto, Salvador Berumen y Luis Felipe Ramos (2011), Apuntes sobre Migración, núm. 1, México, INM. 